EPiC Series in Language and Linguistics
Volume 3, 2018, Pages 110-116
LSP in Multi-disciplinary contexts of
Teaching and Research. Papers from the
16th International AELFE Conference

\title{
Needs analysis and competence profiling through ethnographic methods: the case of the Academic English course at the Graduate School of a Spanish university
}

\author{
Ignacio Guillén Galve \\ Universidad de Zaragoza, Zaragoza, Spain \\ iguillen@unizar.es
}

\begin{abstract}
This paper reports findings from a micro-ethnographic study of the academic literacy practices of the doctoral students that participate in the course in Academic English (AE) taught at the Graduate School of the University of Zaragoza (UZ), Spain. So far there is no evidence regarding the degree of competence in spoken and written communication in academic English to be expected from the students that enroll in the course. Accordingly, the UZ has funded a Teaching Innovation Project (TIP) with the aim of developing ethnographic study protocols capable of providing empirical data on competence profiles, and analysing the learning needs of a specific type of EFL adult learner. The aim of this paper is, therefore, to report on those results that can help to improve the AE course by planning it more efficiently on the basis of a needs analysis that takes disciplinary factors, among others, into account. Reading specialized bibliography, writing a dissertation, giving an oral presentation... all seem to constitute manifestations of, or generic competences for, Academic English in tertiary education, but the acquisition of those competences in an EFL environment may become a challenge for the young researcher attending the AE course. Nowadays, effective teaching in that context requires going beyond mere experience and gathering empirical, ethnographic information suitable for competence profiling (see e.g. Bocanegra-Valle, 2016). Consequently, our study draws on relevant ethnographic techniques in the field of EAP (see e.g. Dressen-Hamouda, 2012), the paper thus beginning by reporting on the results of the analysis of the answers to a structured questionnaire administered to students as the starting point for small-scale semistructured interviews. Our ultimate aim is the examination of the acquisition and learning of second-language academic literacy practices in line with e.g. 'New Literacies' studies such as Seloni (2012).
\end{abstract}


Keywords: literacy practices in EFL/EAP ; needs analysis in EFL/EAP ; competence profiling in EFL/EAP ; Academic English for doctoral students

\section{Introduction}

This is a research-in-progress paper which is intended to add to the literature on needs analysis for competence profiling regarding the design of an Academic English (AE) course for doctoral students in an English as a Foreign Language (EFL) context, the Graduate School of the University of Zaragoza (UZ), Spain. So far there is no qualitative evidence regarding the degree of competence and the competence profiles in spoken and written communication in academic English to be expected from the students that enroll in the course. Accordingly, the UZ agreed to fund a one-year Teaching Innovation Project (TIP) with the aim of developing ethnographic study protocols capable of providing empirical data on competence profiles, and analysing the learning needs of the above type of EFL adult learner. The aim of this paper is, therefore, to provide a preliminary report on those results that can help to improve the AE course design by planning it more efficiently on the basis of a needs analysis.

The theoretical and methodological foundations of the present study go back to one of the classic perspectives on English for Specific Purposes (ESP), Hutchinson and Waters (1987). A key element taken from the book for this study is the authors' notion that "ESP [...] is an approach to language learning in which all decisions as to content and method are based on the learner's reason for learning". We believe that one of the best current proposals regarding Hutchinson and Water's decision-making process is Bocanegra-Valle's (2016) comprehensive account of needs analysis (NA). Her definition of NA is particularly pertinent to our goals because NA is said to refer to "the systematic investigation of needs for the design of a language course and the optimisation of language teaching and learning" (Bocanegra-Valle, 2016, p. 560). This definition is accompanied by a precise "needs analysis process" (Bocanegra-Valle, 2016, p. 563, Figure 42.2) (NAP henceforth). In the design of the AE course at UZ, there have been so far neither real target situation nor discourse analyses (the first two stages in Bocanegra-Valle's NAP), since the instructors have for the most part designed materials directly on the basis of their own general observation and experience as ESP/EAP practitioners or the work of well-known researchers in the field (in terms of breadth of coverage of genres or approaches).

It is my contention here that the most productive way of carrying out the necessary target and learning situation analyses for the AE course in question is the implementation of a microethnographic, qualitative study of the academic literacy background and practices of the doctoral students that participate in the course. The present study is, therefore, based on the administration of a structured questionnaire as the starting point for small-scale semi-structured interviews. Our study is not new either in terms of sources or in terms of research instruments and, as a result, there might be doubts about the validity or pertinence of both; however, in Bocanegra-Valle's (2016, pp. 562-567 \& Table 42.1) exhaustive sample of the latest research on EAP needs analysis, there are not very many studies that focus on postgraduates, let alone doctoral students, and the author herself points out that "questionnaires are used in all cases and interviews rank as the second most preferred data collection technique". In addition, Odena and Burgess (2015) have recently demonstrated that there is an expanding body of publications on developing writing skills with a focus on postgraduate students, and on approaching the topic from the students' viewpoint.

As regards the reason why we thought that the use of a questionnaire could become the starting point for small-scale semi-structured interviews, we were influenced by the results of Dacia DressenHamouda's (2012) study of international journals in ESP concerning the identification of research reports that have used qualitative and/or ethnographic methods, where studies were identified "as 
using qualitative methods if authors used at least one, if not a combination of, qualitative methods including: surveys, questionnaires, interviews, case studies, textography [...]" (Dressen-Hamouda, 2012, p. 506; my italics).

A type of learning situation analysis (LSA) particularly suitable for the AE course at the Graduate School of UZ is that put forward by Brian Paltridge and his collaborators (2009, pp. 50-51) in their introduction to the teaching of academic writing, since their book was written for teachers of second language writers. The LSA of our study concentrated on those aspects relevant for the analysis of EFL doctoral students' needs: their language learning, educational and literacy backgrounds as well as language learning goals, levels of language proficiency and writing ability (among other skills), including their knowledge of target tasks per skill. These aspects of LSA partly determined the general structure and contents of the questionnaire described in the Methods section below, whereas other more concrete components of the questionnaire such as its competency lists drew on the Can Do Framework for EAP syllabus design and assessment (CDF) published by the British Association of Lecturers in English for Academic Purposes (BALEAP). We had to 'adapt' rather than 'apply' the BALEAP's framework because the CDF is based on research into the "competencies" (the term used in the CDF) required by students studying in UK universities at Master's level, whereas the present paper is about needs analysis and competence profiling for a course with a largely monolingual group of EFL doctoral students ( $87 \%$ of the respondents indicated Spanish as their native language).

\section{Methods}

Our questionnaire, which was implemented with the technology of Google Forms, consisted of 4 sections and 25 items (questions). Section 1 was concerned with students' personal information (age, sex, their native language as well as their parents', years of study of English at university level, and certified knowledge of English). Section 2 consisted of questions relating to the students' specific field of academic study. Section 3 had a complex nature, since it was intended to delve into the student's personal relationship with the study and use of academic English. Accordingly, the first item in the section invited students to consider whether their relationship with English was merely academic as part of their enrollment in a doctoral programme, whether it was part of their research career, or whether it was rather a professional matter. The next item aimed at determining what the predominant factor in their relationship with the English language was at this stage of their lives (i.e. as doctoral students): a personal decision or choice, a necessity, mere compliance with an academic requisite, or one more stage in their experience as EFL learners. The next two questions sought, on the other hand, more objective, skill- and task-oriented answers (e.g. whether English was only relevant for writing purposes, or whether they had had to use it while attending conferences), including the option of selecting the extended negative answer 'no, but it would suit me to use English for this purpose', the aim of which was to gather preliminary information about the learners' views of what they thought they needed to be able to do in English. Finally, Section 4 (competencies) consisted of a multipleanswer table divided into the four skills of Writing, Speaking, Reading and Listening.

As a tool for needs analysis, the structure of certain sections or items in the questionnaire reflects the type of methodology to be found in studies such as Liu, Chang, Yang and Sun's (2011) exploration of EFL college students' needs from six university programs in Taiwan. We decided to adapt Liu et al.'s methodology to our study because their study also built on Hutchinson and Waters' (1987) three subcategories of needs: necessities, lacks, wants, and had similar objectives, i.e. a categorized and learner-centered investigation of needs (see Liu et al., 2011, p. 273), although, in our case, those students' needs in a Graduate-School-level AE course. According to Paltridge et al. (2009, p. 49), "necessities are the type of needs that are determined by the target situation - that is, what the learners have to know and be able to do to function effectively in the target situation". In our study, 
the analysis of necessities amounted to the adaptation of the BALEAP Can Do Framework (CDF), since, from the range of competencies that make up each skill in the CDF, we only selected those categories which were close to the kinds of 'skill tasks' EFL doctoral students need to engage in. As the CDF is aimed at Master's level, the selection (or adaptation) of items (competencies) for our questionnaire was carried out by a team made up by two instructors from the course itself, two doctoral students from the Doctoral Programme in English Studies at UZ who had participated in the 2015/16 edition of the course, and a researcher familiar with qualitative methodologies (see Acknowledgments section below). Before the doctoral students from the present edition (2016/17) of the course were invited to complete the questionnaire, a third student from the Doctoral Programme in English Studies, who was about to defend a PhD thesis in the field of literature and was not, therefore, familiar with research concerns in the area of ESP, acted as a neutral 'pilot' student.

While Section 4 ('competency areas') is the largest one in the questionnaire, and was, therefore, placed at the end, the previous ones are equally meaningful because they gather information on "lacks", among other aspects. According to Paltridge et al. (2009, p. 49), the "lacks" refer to "what the learners know and can do already and the gap between this and what they need to be able to do"; for this reason, learners' previous literacy experiences were initially elicited by means of the additional questions in Section 1 about the number of years of study of English after the students began their degree studies, and about certified knowledge of English (in terms of e.g. Cambridge English Language Assessment).

"Wants", on the other hand, refers to "the learner's views of what they need, or want, to be able to do in English. This requires a learning situation analysis, which provides information on learners' subjective, or felt needs". This is the reason why each item in the 'competency areas' Section was followed by six possible answers which were, in order of appearance, 'no', 'no, and besides I don't think this goal is a necessity', 'yes, very occasionally', 'yes, sometimes', 'yes, often', and last, as an extension of the affirmative answer, 'in my case, I also believe that this goal is one of my big deficiencies in my use of the English language'. The incorporation of the notion of "goal" into the set of answers stems from Paltridge et al.'s (2009, p. 49) statement that "[a]n examination of wants also includes the collection of information on students' learning goals" as they "may vary from those of the teacher". Consequently, the extension of the negative answer into the 'not-a-necessity' specification was intended to identify possible areas of conflict between learners and course designers.

Once the structure, contents and wording of the questionnaire had been fully discussed and piloted, the 84 students that had enrolled in the 2016/17 edition of the AE course were sent an e-mail message in which the coordinator of the course invited them to complete the survey on Google Forms anonymously. The number of respondents was $45,53 \%$ of the students that followed the course. Their answers were received between March 2nd and March 15th 2017. Finally, as regards the small-scale semi-structured interviews that followed the implementation of the questionnaire, we considered them to be a possible starting point for the production of a type of study similar to Lysia Seloni's (2012), which has a clearer ethnographic orientation and methodology (a 'New Literacies' one).

\section{Discussion of findings}

As regards the 37 competencies (goals, communicative objectives) included in the Competency Areas Section of the questionnaire, the most relevant finding is that not very many competencies were identified by students as 'not-a-necessity' (27\%), and then by few students (less than $10 \%$ ). These figures seem to indicate that there is a high degree of agreement about "necessities" between students and teachers (here in terms of our use of the BALEAP Can Do Framework to determine the set of competencies necessary for the AE course). None of those 'non-necessities' concern Reading, which is not a problematic area in terms of "wants" either. An explanation for the students' choice of 'non- 
necessities' may be that these competencies can be judged to be too general or unrelated to EFL or, in terms of the English version of the Common European Framework of Reference for Languages, Chapter 2, distant from the idea of "communicative language competences" or from usual doctoral student activities or situations.

In terms of "present situation analysis", which is part of "lacks", item no. 6 in the questionnaire revealed that a relatively high number of students (61\%) had been studying English (EGP) for only 5 years or fewer after entering university for their degree studies, and that only a fifth of the respondents had been studying English for 10 years or more. As regards the variable of 'certified knowledge of English' (item no. 7), about a quarter of the respondents (27\%) answered that they had no certificate, only $11 \%$ of the rest having reached the $\mathrm{C} 1$ level and then not all holding a certificate from wellestablished institutions such as Cambridge English Language Assessment (CELA). In our view, the age/years of study complex is a reliable indicator that the AE course classes are likely to be mixedabilities ones, with the instructors having to make every effort not to turn the AE lessons into EGP ones. A reason for this may be the typically high average age of the students participating in Spanish doctoral programmes, with a significant third of our respondents within the 31-40 year-old range, and just above half of them (58\%) within the 23-30 year-old range, which is the range closer to the year of completion of a Master's degree. Consequently, the curricular planning of the course should take account of the fact that its average student will be one with a discontinuous relationship with the formal study of English as a Foreign Language, and will not be a proficient user on the basis of what having an EGP C1 certificate may entail (see e.g. CELA's webpage for their Certificate of Advanced English, CAE) for adequate performance in an academic English course at doctoral level.

Another significant finding was that $38 \%$ of the respondents were interested in 'using' English not only because they were doctoral students, but also as young researchers; those that extended 'using English' to their professional life beyond academic and research needs were a significant $20 \%$. The results from the above item of 'scope' matched those obtained for 'motivation', the next item in the questionnaire. 33\% of the respondents stated that they were studying English, now as part of an AE course, "out of necessity"; 29\% chose the "as a personal choice" answer, and 27\% argued that their enrollment in the course was an academic requisite for successful achievement in their doctoral programme. Only $11 \%$ regarded their participation in the course as one more stage in their life as EFL learners. Accordingly, taking the AE course does not seem to be motivated basically by compliance with a certain academic requisite or the culmination of EFL learning. Reasons such as necessity and personal choice constitute a strong enough motivation to compensate for previous weak or moderately weak literacy experiences in EFL.

The results in terms of "lacks" showed that not all 'tasks' or 'activities' which we thought as plausibly associated with doctoral students' academic life in English were part of the respondents' experiences. While in a previous item $47 \%$ of the respondents indicated that they used English, as can be expected, for purposes related to the four skills (use of English for only one, two or three skills was indicated by far fewer respondents, $16 \%$ for Reading and 13\% for Reading- Listening-Speaking), certain tasks were not chosen by respondents as typical instances of the use of English among doctoral students. For example, $40 \%$ denied having used English for handling administrative or managerial tasks; $60 \%$, for helping to broker research or financial partnerships, and an even higher group (69\%) came up concerning the writing of fund-raising proposals, although $13 \%, 33 \%$ and $16 \%$ of the respondents, respectively, chose 'no' but admitted that it would suit them to be able to use English for those purposes. Similarly, $71 \%$ of the respondents stated that they had not participated in the activity of reviewing or evaluating manuscripts written in English, but a significant $40 \%$ of them indicated that it would suit them to be able to do so. Accordingly, these data can help to identify the tasks that should become the focus of a new or special target situation analysis for the AE course and its curricular planning.

On the other hand, other activities such as searching the WWW for information in English as part of a literature review in the same language were said to have been carried out by more than $60 \%$ of 
the respondents $(100 \%$ as regards Internet searches in English, $76 \%$ for the writing of abstracts and publication proposals in English, and between $60 \%-70 \%$ for the writing of poster presentations or for spoken interaction in the language during fieldwork, conferences or research group meetings). These activities refer, therefore, to areas less relevant for the curricular revision of the design of the $\mathrm{AE}$ course.

Finally, the results in terms of "wants" suggest that the AE course at UZ should be renewed to favour Speaking instruction in particular and, to a lesser extent, Listening and Writing. This conclusion is similar to one of the lessons learned by Taillefer (2007), who, according to BocanegraValle (2016, p. 564), found out that "[o]ral communication is perceived as the most difficult skill". The answers to the competency area of Speaking revealed that this area gathers up to six of the competencies which were identified as 'big-deficiencies-in-my-use-of-English' by respondents, with percentages ranging from $22 \%$ and $16 \%$ : for example, $20 \%$ selected the competency of participating in a conversation or debate at a laboratory or seminar. As regards Listening, $22 \%$ of respondents indicated that one of their big deficiencies was the ability to understand an adequate enough amount of information (in terms of detail and speed) to participate critically in a conversation or debate, whereas the only other 'deficiency' competency in the area $(18 \%)$ was a classic one, note-taking. Writing competencies were less significant as percentages of respondents were slightly lower, with $16 \%$ focusing, for example, on the ability to understand the conventions of academic English (formality, objectivity, etc.), with, again, one sole other competency. Lastly, the Reading area only contained one competency judged to be one of their personal deficiencies by respondents: feeling control of vocabulary and syntax at the advanced level required by academic English, 18\%.

\section{Concluding remarks}

The above findings clearly show, on the one hand, that our adaptation of the BALEAP Can Do Framework concurs to a large extent with the students' own evaluation of those competencies as "necessities". On the other hand, "wants", while not being particularly serious (as the percentages of respondents that identified competencies as personal 'deficiencies' were always lower than 25\%), cannot be ignored because they seem to cluster round certain competency areas or skills, Speaking in particular, with Reading as the least problematic one. Therefore, it is the "learning situation analysis" concerning the students who attended the 2016/17 edition of the Academic English course that proved to be really meaningful and contributed to competence profiling, whereas, according to the results of our study, the course designers' new "target situation analysis" should focus more on determining the micro-skills, strategies and (linguistic) knowledge involved in the "necessities" rather than on the mere "determination of necessities".

\section{Acknowledgements}

In my capacity as Coordinator of the Teaching Innovation Project (TIP) that sustains the present study, I would like to thank all the members of the working party of the TIP for their invaluable expertise in key areas for the development of the project; Dr. Ana Bocanegra-Valle, from the Universidad de Cádiz, for providing a very useful bank of bibliography; Drs. Ignacio Vázquez and María-José Luzón, from the Universidad de Zaragoza, instructors in the Academic English course, for their insights and expert advice in the areas of EAP/ESP; Dr. Oana Carciu for her experience with survey applications as well as her knowledge of qualitative methodologies; and doctoral students María Ferrández, Marian Velilla and Rosana Villares for their efficient piloting and learner-level 
insights. This work is also a contribution to national Research Project FFI2015-68638-R MINECO/FEDER, EU, funded by the Spanish Ministry of Economy and Competitiveness.

\section{References}

Bocanegra-Valle, A. (2016). Needs analysis for curriculum design. In K. Hyland \& P. Shaw (Eds.), The Routledge Handbook of English for Academic Purposes (pp. 560-576). Abingdon, Oxon: Routledge.

British Association of Lecturers in English for Academic Purposes. (2013, April). BALEAP Can Do Framework: Competency statements for international students (Master's level). Retrieved from https://www.baleap.org/projects/can-do

Dressen-Hamouda, D. (2012). Ethnographic approaches in ESP. In B. Paltridge \& S. Starfield (Eds.), The Handbook of English for Specific Purposes (pp. 501-518). Oxford: Wiley-Blackwell.

Hutchinson, T. \& Waters, A. (1987). English for Specific Purposes. Cambridge: Cambridge University Press.

Liu, J. Y., Chang, Y. J., Yang, F. Y., \& Sun, Yu. C. (2011). Is what I need what I want? Reconceptualising college students' needs in English courses for general and specific/academic purposes. Journal of English for Academic Purposes 10(4), 271-280.

Odena, O. \& Burgess, H. (2015). How doctoral students and graduates describe facilitating experiences and strategies for their thesis writing learning process: a qualitative approach. Studies in Higher Education, 42(3), 572-590.

Paltridge, B., Harbon, L., Hirsch, D., Shen, H., Stevenson, M., Phakiti, A., \& Woodrow, L. (2009). Teaching Academic Writing. An Introduction for Teachers of Second Language Writers. Ann Arbor, MI: The University of Michigan Press.

Seloni, L. (2012). Academic literacy socialization of first year doctoral students in US: A microethnographic perspective. English for Specific Purposes, 31(1), 47-59.

Taillefer, G. F. (2007). The professional language needs of economics graduates: Assessment and perspectives in the French context. English for Specific Purposes, 26(2), 135-155. 